\title{
DOES CONVERGENCE LIBERALISM RISK ANARCHY?
}

\author{
Marcus Schultz-Bergin
}

$\prod$ UBLIC REASON, or political, liberals argue that coercive social arrangements must be publicly justified in order to be legitimate. ${ }^{1}$ On the traditional "consensus" model of public reason most commonly associated with John Rawls, this means that such arrangements must be justified by appeal to a set of "public reasons" that are shared by, or accessible to, all reasonable citizens. On the more recent convergence model, however, an arrangement may be publicly justified so long as every citizen has sufficient reason of her own to accept the arrangement, even if those reasons are not shared by other members of the public. $^{2}$ The corollary of this change in justification is that, on the convergence model, non-shared reasons may also function as defeaters: in contrast to the consensus model where (for instance) religious reasons play no role in justifying or defeating laws, on the convergence model they may form a patchwork of justification or function all on their own as reasons to reject a law. ${ }^{3}$

This ability to leverage non-shared reasons to defeat laws has led critics, most notably David Enoch, to argue that convergence models are incapable of vindicating liberalism. They argue that someone will have a defeater for every possible law, and so the convergence model leads to anarchy-the view that no law is legitimate. ${ }^{4}$ Relatedly, some critics suggest that convergence models can, at

1 There is disagreement among public reason liberals as to what, precisely, stands in need of justification: the basic structure of society, constitutional essentials, laws, moral rules, etc. I use the phrase "coercive social arrangements" as a catchall, but will occasionally reference more precise instances (such as laws) for convenience's sake. Nothing I say, except in section 6, turns on the precise sort of arrangement we are considering.

2 It is worth flagging here that I have only said convergence views permit "non-shared" reasons. I have not claimed convergence views permit "non-accessible" reasons since it is an open debate among convergence liberals whether that is true and exactly what that means. But for the purposes of this paper it does not really matter what position we take on that debate.

3 Gaus and Vallier, "The Roles of Religious Conviction in a Publicly Justified Polity."

4 Enoch, “Against Public Reason." See also Wall, “Public Reason and Moral Authoritarianism." 
best, only vindicate the minimal state and, therefore, make libertarians "dictators" since they will defeat any law beyond their minimal preferences. ${ }^{5}$

My aim in this paper is to defend convergence liberalism against this anarchy objection. Using Enoch's presentation of the objection as the exemplar, I argue that we should reject both premises of the objection. By and large, I suggest, the anarchy objection rests on misunderstandings or misrepresentations of the convergence model. In the process of responding to the anarchy objection, then, I will also be clarifying key elements of the convergence model. My response is largely a general response on behalf of all convergence models of public reason.

However, in section 6 I will argue that a full response to the anarchy objection requires adopting the "wide scope" position in the scope debate among political liberals. Currently, there is debate as to what sorts of coercive social arrangements - constitutions, laws, social-moral rules, etc.-are subject to public justification. Although there are a variety of considerations to this debate, my argument will provide a distinct reason in favor of the view that all coercive social arrangements should be subject to public justification. To that end, consideration of the anarchy objection can help us make progress in the development of convergence liberalism (and political liberalism more generally). I further argue that, in overcoming the anarchy objection, the resulting view of convergence liberalism is much more open to views and policies commonly associated with "social justice liberalism" than is traditionally thought.

\section{THE ANARCHY OBJECTION TO CONVERGENCE LIBERALISM}

For public reason liberals, the exercise of legitimate authority is constrained by a public justification principle ( $\mathrm{PJP})$. The exact content of that principle varies among different theorists, but a general statement of the PJP holds that:

A coercive social arrangement $S$ is justified in a public $P$ only if each member $i$ of $P$ has sufficient reason $(\mathrm{s}) R_{i}$ to endorse $S .^{6}$

Convergence liberals and consensus liberals differ on how they interpret some of the variables in the PJP. Two of these differences, the interpretations of $R$ and $P$, are what lead to the anarchy objection. First, convergence liberalism allows non-shared reasons to function within public justification. Second, convergence liberals endorse a moderate conception of idealization, rather than the more substantial or radical forms of idealization favored by consensus theorists. These two features together mean that the set of reasons that can function to both jus-

5 Lister, "Public Justification and the Limits of State Action."

6 Vallier and D’Agostino, "Public Justification." 
tify and defeat laws is significantly larger than under the consensus conception. Idealized members of the public are understood to hold onto many more personal beliefs and those personal beliefs are relevant to public justification.

Convergence liberals argue that their approach better fits with the underlying motivations for public reason liberalism. ${ }^{7}$ For Rawls, the public reason project arose out of two observations: the fact of reasonable pluralism and the freedom and equality of all persons. ${ }^{8}$ The freedom and equality of all persons drives the requirement to justify any coercive authority exercised over them while the fact of reasonable pluralism shows the difficulty in establishing that justification. Convergence liberals note that the consensus liberal solution effectively jettisons the fact of reasonable pluralism by substantially idealizing members of the public to the point where they are effectively the same person. ${ }^{9}$ Moreover, consensus approaches fail to fully respect persons as free and equal since they require citizens to ignore those beliefs and values that make them distinct individuals. ${ }^{10}$ Convergence liberalism, on the other hand, aims to genuinely respect the fact of reasonable pluralism and the freedom and equality of all persons by maintaining a significant amount of evaluative diversity even after idealization.

While this move to moderate idealization and convergence justification may be well motivated, even convergence liberals recognize it has a "troubling dark side." ${ }^{11}$ As Christopher Eberle observes, convergence models include "an extremely demanding understanding of what makes for justified coercion-if there is only one coerced citizen who has conclusive reason to reject [a law], then [the law] is morally wrong, even if [the law] would be justified absent that

Vallier, "Against Public Reason Liberalism's Accessibility Requirement," "Convergence and Consensus in Public Reason," and "In Defence of Intelligible Reasons in Public Justification.” Importantly, I am merely relaying some of the arguments made by convergence liberals against consensus views, not endorsing them. Nothing in my argument will turn on the success of these criticisms.

8 Rawls, Political Liberalism, xviii.

9 Rawls effectively says as much about the parties to the original position; A Theory of Justice, 118-29. Quong endorses something similar in Liberalism without Perfection and "Liberalism without Perfection." Gaus makes something like the "same person" charge in The Tyranny of the Ideal, ch. 2. However, it should be noted that Rawls's larger view in Political Liberalism adds steps beyond the Original Position that involve less radical idealization. Quong's development of Rawlsian public reason liberalism, though, puts more emphasis on Original Position reasoning and thus gets closer to maintaining the "same person" concern that arose in A Theory of Justice.

Both Gaus and Vallier make this "alienation” charge: Gaus, The Order of Public Reason, 238; and Vallier, Liberal Politics and Public Faith, ch. 2.

Vallier, "Convergence and Consensus in Public Reason," 268. 
lone dissenter." ${ }^{12}$ When you combine sufficient evaluative diversity with an extremely demanding requirement of public justification, it seems quite obvious that many, and perhaps all, laws will fail to pass the test. And it is that seemingly obvious fact that motivates the anarchy objection.

David Enoch's statement of the anarchy objection begins with an observation of actual citizens and political debate in modern diverse societies. He suggests that such citizens are a "very varied bunch" with such diverse commitments that "if the justifications offered to them are to engage them as they actually are ... then it's hard to believe that there is anything at all that can be justified to all."13 Thus, he argues, without some form of idealization, anarchism results. Perhaps he is right, and in any event, we can accept this conclusion as far as it goes.

But Enoch also believes that convergence liberalism, with its emphasis on moderate idealization, will also result in anarchy. In particular, he argues that if we stick with a moderate theory of idealization, "the price would be anarchism again — for among those who are reasonable in just some very thin sense of this kind, everything is controversial ... [and] nothing is justifiable to all the reasonable in this sense." ${ }^{14}$ Although he does not offer a substantial argument for this claim - resting it largely on the reader's sympathy to the idea- he is not alone in drawing this conclusion and it appears to have significant intuitive appeal. ${ }^{15}$ As such, it is vital for convergence theorists to have a clear response to this anarchy objection.

As I see it, Enoch's argument takes the following form:

1. Among moderately idealized members of the public, everything is controversial.

2. If everything is controversial, then nothing is justifiable.

3. Therefore, among moderately idealized members of the public, nothing is justifiable. ${ }^{16}$

We have good reason to doubt the truth of both premises, and in the course of my response I will argue that both are false. To begin, however, I will accept the truth of premise 1 and focus on premise 2, which I think is the more immediately intuitive premise since it takes much of its support from observation of actual

Eberle, “Consensus, Convergence, and Religiously Justified Coercion,” 289.

Enoch, "Against Public Reason," 117-18.

Enoch, “Against Public Reason,” 122.

E.g., Raz, "Facing Diversity," 46; Lister, "Public Justification and the Limits of State Action."

Steven Wall's version of the anarchy objection, leveled specifically against Gaus's convergence theory, has effectively the same structure. See Wall, "Public Reason and Moral Authoritarianism," 168. 
political debate and actual citizens. I will turn to evaluating premise 1 in sections 4-7. My argument against premise 2 rests, broadly, on the claim that it depends on two misunderstandings of convergence liberalism. Once these two misunderstandings are clarified, we will see that convergence liberalism is well placed to deal with a society in which everything is controversial.

I will consider each misunderstanding of convergence liberalism separately, first focusing on how the premise misunderstands the notion of sufficient reason and, second, how it ignores convergence liberalism's insight that bare social coordination has moral and prudential value for all. With these two elements combined, we will be able to say that all "members of the public"- the name given to the moderately idealized public_-despite total disagreement, will have sufficient reason to endorse key institutions of classical liberalism such as a system of private property. ${ }^{17}$

\section{DISAGREEMENT AND SUFFICIENT REASON}

Aly, Barry, and Chris are discussing dinner options. Aly, a committed vegan, strongly prefers a plant-centered restaurant while Barry is a meat-and-potatoes guy who strongly prefers a meat-centered restaurant. Chris is quite open to various options, caring much more about the social aspect of dinner than the food itself. Aly, Barry, and Chris are, in Enoch's words, a "very varied bunch," and so, on his view, even if they were moderately idealized, there would be no dinner option justifiable for them all.

We can motivate Enoch's position by considering how the dinner debate may go. Aly and Barry, with their strong and conflicting preferences, will stump for their preferred options. Barry may, in this debate, insist that he will only attend a dinner at a steakhouse while Aly will insist that she will only attend a dinner at a new vegan restaurant. In public reason terms, we may be tempted to say, as Enoch does, that only the new vegan restaurant is justifiable for Aly while only the steakhouse (or steakhouses) is justifiable for Barry. If this is indeed the case, then it does appear that nothing is justifiable for them all.

But this analysis of the situation is a mistake. While it is true that Barry and Aly disagree about which option is best — and we will assume such disagreement will survive moderate idealization - it is incorrect to assume that only their most preferred restaurant is justifiable for them all. A key element of the convergence model is that members of the public may have sufficient reason to endorse a pro-

17 Gaus introduces the phrase "members of the public" to describe the idealized public but it has been adopted by other convergence liberals as well. See, e.g., Gaus, The Order of Public Reason, 267; Vallier, Liberal Politics and Public Faith and Must Politics Be War? 
posal-Aly and Barry may have sufficient reason to endorse a restaurant- that they nevertheless find suboptimal. And while in actual political debate we may, for strategic reasons, suggest that we will only accept our most preferred option, it is incorrect to read that sort of saber rattling into the public justification principle and its requirement that all moderately idealized members of the public must have sufficient reason to endorse a coercive social arrangement.

The aim of public justification is to reconcile the status of all people as free and equal with the authority we, as a society, exercise over each other. But since a society of free and equal people will necessarily be characterized by reasonable disagreement, we cannot expect everyone to agree on what is best. The whole point of a theory of public justification, then, is to provide "an account of how people who disagree on the best may still come to endorse a common rule." ${ }^{18}$ Thus, any plausible theory of public justification must, by necessity, allow for the public justification of rules that some (or all) consider suboptimal. This also fits with our general understanding of what it means to live in a society. We commonly think that living with others requires "compromise"-it means not always getting what you believe is ideal. ${ }^{19}$ But, of course, we also do not think that living in a society should require you to "compromise on your principles," and so it does not require living in accord with norms or rules that you find wholly unacceptable.

The above reflection on the point of, and underlying motivations for, public justification has direct implications for the construction of the deliberative model we use to investigate what sorts of policies pass the test of the PJP. Although convergence liberals construct the deliberative model somewhat differently, I will mostly draw on Gerald Gaus's construction in The Order of Public Reason, as it provides the most developed view and has been more or less adopted by most convergence liberals. ${ }^{20}$ In our dinner example, we begin by constructing a ranking of options for each individual: clearly Aly ranks the new vegan restaurant as best while Barry ranks the steakhouse as best, but all three friends have other options on their rankings. To construct these rankings, we do not simply consider "Where do you want to go for dinner?" but instead construct a ranking based on pair-wise comparisons. ${ }^{21}$ Like an eye exam where one cannot judge whether a lens correction is better without having another option to compare, the relevant question is "Would you prefer to go to dinner at restaurant A or restaurant B?" and so on for the various options. When the choice situation is modeled in this

18 Gaus, "On Two Critics of Justificatory Liberalism," 204.

19 See, e.g., Wendt, Compromise, Peace and Public Justification.

20 Gaus, The Order of Public Reason, ch. 5.

21 Gaus, The Order of Public Reason, 304. 
way, we can start to see how additional options get added to each individual's rankings: Would Aly prefer to go to the steakhouse Barry recommends or would she prefer an exotic-meats restaurant? Would Barry prefer the vegan restaurant Aly recommends or would he prefer Chinese takeout?

But of course some options may be totally unacceptable. Aly, for instance, may be unable to eat a meal at the exotic-meats restaurant, and so we need some way of modeling the idea of an option being totally unacceptable. The commitment to the freedom and equality of all people establishes this baseline. Since no person is naturally under the authority of any other, for any given issue the natural baseline is one where each acts in accord with her or his own judgment and there is no common policy on the given matter. ${ }^{22}$ It is always deviations from this baseline of natural freedom that stand in need of public justification. Each exercising her natural freedom need not be justified. And so, in the choice situation Aly, Barry, and Chris face, the natural baseline is that they do not go to dinner together at all. Naturally, if they cannot agree to a common place, they will go their separate ways. And for some of the possible options, such as the exotic-meats restaurant, some of the individuals would prefer to forgo the social dinner. For Aly, the exotic-meats restaurant is worse than no social dinner at all.

Notice the cost Aly pays for ranking the exotic-meats restaurant below the baseline. She, Barry, and Chris had first agreed to go to dinner together. They did this for a variety of reasons, not just because they were hungry. Although Chris is quite laid back about the food choices and cares a great deal about the social element, both Aly and Barry are also motivated by the social element of dinner. To rank the exotic-meats restaurant as worse than no dinner at all is not simply to refuse to eat exotic meats, it is to refuse all the other benefits that come along with a social dinner. Obviously Aly may have to make such a refusal in this case. But the important lesson to draw out is that ranking a proposal as worse than no common rule at all is no simple matter. It is not akin to the sort of "my way or the highway" saber rattling that is characteristic of actual political debate, where we may be blustering for strategic reasons, fully knowing that at the end of the day we will end up with some common rule. To suggest that an option is totally unacceptable is to forgo all the benefits that you attach to having a common rule at all.

Aly, Barry, and Chris all have sufficient reason to endorse any of the restaurant options that they prefer to not going to dinner at all. Given that each of them has some preference for going to dinner with each other-analogous to members of the public having some preference for living in society with one another-they all are likely to have a variety of options on their list. From this, 22 Gaus, The Order of Public Reason, 311-13. 
we could construct a social ranking, identifying the options that are on all three lists. This would not determine which restaurant they should go to, but it would identify the set of eligible options. At that point, which one they select is not terribly important, for any of the restaurants would be justified for them all. ${ }^{23}$

The preceding discussion illustrates why Enoch's second premise is false. For Aly, Barry, and Chris, it was genuinely controversial which restaurant to patronize. But it did not follow that no option was justifiable for them all. Although Barry may claim, in discussion, that he refuses to eat at a vegan restaurant, to actually refuse such an option is to also refuse the company of his friends, and when the choice is put that way we can see why the vegan restaurant may very well be on his list of acceptable proposals. ${ }^{24}$ Now, importantly, this discussion of sufficient reason is not meant to show that there is some justifiable arrangement with regard to all controversial matters. In certain situations, it may actually be that there is not a single proposal shared among all members of the public. If Aly and Barry do not really care to eat together, or care much more about getting their way than eating together, then maybe they will not be able to coordinate on any option. But merely disagreeing about what is best does not mean that nothing is justifiable.

There is, however, a further point to make about core liberal institutions. So far, Aly, Barry, and Chris have been considering restaurants that are heavily vegan focused or heavily meat focused. But now Chris suggests an Indian restaurant, which has a variety of meat and vegetable curries. In fact, the menu is split nearly in half between vegan options and meat options. Aly has a wide variety of vegan options to choose from while Barry has a variety of meat options to choose from. What was initially a collective decision over whether to eat vegan or not has now become an individual one. While there must still be a collective decision over the specific restaurant, at least one of the major issues that the friends were get-

23 Convergence models are a bit more complex than this. In particular, most endorse a Pareto rule that holds that if an arrangement is dominated by another arrangement in every member of the public's eligible set, then it is not part of the socially eligible set. Additionally, how a member of the socially eligible set becomes the norm can matter. If it is made the norm by a non-publicly justified decision rule, then it is still not publicly justified. But if it is "selected" by way of a publicly justified decision rule or as a result of social evolution, then it is publicly justified.

24 Those familiar with game theory will recognize that this is an example of a (slightly modified) Battle of the Sexes game where players disagree about what they should do but have an interest in doing something together. However, whereas in the standard Battle of the Sexes game players receive zero payout for not coordinating, I leave open that there may be some minimal payout for "eating alone." But the central point of the game, that an interest in doing something together can mean a player receives a positive payout even when they are not doing what they really wanted to do, still holds. 
ting hung up on has been sidestepped. Or, more precisely, the decision has been "devolved" from the collective to the individual. This sort of devolving of authority is precisely what makes liberal institutions, such as private property regimes, so well placed to deal with evaluative diversity. As Gaus explains:

A deeply pluralistic social order can effectively cope with many of its disagreements about what evaluative standards to adopt by establishing a system of private property... Given the problem of evaluative pluralism ... each Member of the Public has a fundamental interest in instituting a system whereby the natural and social world is divided into different jurisdictions in which the evaluative standards of the ... rightholder ... will be determinative. ${ }^{25}$

Rather than Aly being beholden to Barry's dietary preferences, or Barry being beholden to Aly's, Chris has suggested an option that allows each of them to remain their own dietary master while still gaining the benefits of a friendly social dinner.

In the political realm, the schemes of rights and liberties that characterize a liberal order accomplish the same sort of goal as the Indian restaurant. There can be social coordination around a scheme of rights and liberties, thus establishing a common authority, but that scheme dictates various zones where the evaluative standards of the individual are supreme. In this way, liberal institutions neatly deal with the fact that "everything is controversial." And so, thoroughgoing disagreement need not impugn the public justification of core liberal institutions because such institutions do not involve restricting people's abilities to live their own lives their own way. Rather, they facilitate such an ability by establishing socially recognized jurisdictions of individual authority. Thus, every member of the public will have sufficient reason to endorse some liberal scheme of basic rights and liberties. This is certainly true so long as they have any interest in cooperating or establishing a stable set of social norms. But it remains true (albeit with less force) so long as they have an interest in pursuing their own individual projects and can be understood to see the fact that certain sociopolitical institutions make that possible, likelier, or easier. There will likely still be disagreement over which scheme is best, but so long as there is a non-empty set of socially eligible schemes, then public justification can vindicate the core of liberalism and thereby avoid outright anarchy. 


\section{THE VALUE OF SOCIAL COORDINATION}

Chris never expressed strong dietary preferences. Rather, her main concern was that she, Aly, and Barry have dinner together. She heavily valued social coordination, and so her ranking of various restaurants would likely be influenced more by what she thought both Aly and Barry would agree to than by what sounded tasty to her. Hence her suggestion of the Indian restaurant. There are people like Chris among the general public, who are heavily motivated by a desire for a good social and political community and not so much by a desire to have things "their way." These sorts of people help illustrate the value of social coordination for everyone, and this is important especially for those people who seem to be much more concerned about getting things their way rather than simply coordinating with others. Social coordination, specifically in the form of a liberal scheme of rights and liberties, is good for everyone, and this provides important moral reason for everyone to endorse a common norm over no norm at all, even if they do not believe it is the optimal norm. This shows another way in which we can establish public justification in the face of evaluative diversity.

Let us imagine that Barry has no food at home, and so his only option for eating dinner is to eat out. But Barry also does not like to eat alone. Thus, for him, successfully coordinating with Aly and Chris helps him pursue his individual plan of actually eating. Much of social coordination is like this, especially when the coordination comes in the form of a liberal scheme of basic rights and liberties. Such a scheme establishes a framework under which people may better pursue their own plans and projects. For Barry, agreeing to go to the Indian restaurant-establishing the liberal scheme-allows him to achieve his goal of eating a meat-based dinner with others. He was able to achieve this goal without forcing anyone else to share his goal or otherwise have to forgo their goals. Aly still had her vegan meal and Chris still had a social dinner. Each of these friends had individual aims, and it was the social coordination that made the achievement of these aims possible. This is the moral and prudential value of social coordination, and it is a major reason why diverse individuals have sufficient reason to endorse at least some common authority, and most notably the sort of devolved common authority that is characteristic of liberalism.

The fact of reasonable pluralism is not merely the fact that people disagree. What is more important, socially speaking, is that individuals act based on their beliefs and values, and pursue plans and projects that fall in line with those beliefs and values. If people disagree about fundamental beliefs and values, then it is likely to mean that their ability to pursue their plans and projects will conflict with the ability of others to do the same. If the disagreement remained wholly 
"in the head," as it were, then reasonable disagreement would probably not be much of a concern at all. But it is precisely the fact that people act on their beliefs and values, and that doing so may lead to conflict when people disagree, that makes a liberal scheme of rights and liberties so attractive and essential.

A liberal scheme of basic rights and liberties establishes a framework under which people may better pursue their own plans and projects. By establishing a common understanding of the contours of individual jurisdictions, such a scheme drastically improves everyone's ability to form and carry out their plans. This is because social coordination, particularly around a scheme of basic rights and liberties, drastically reduces the uncertainty that usually accompanies evaluative diversity. Take the example of private property. Without any common understanding of a right to private property, people could still collect and store items. However, there is a much greater risk in doing so since one cannot predict - on the basis of a common understanding of the right of private property-whether others will attempt to take what one has collected. This problem is further magnified when thinking about the pursuit of long-term plans and projects, which often include the collection of various items along the way. The successful completion of a long-term project may depend on many smaller steps of collection and maintenance of items, but if one is quite uncertain whether the items she collected last year will still be in her possession next year, it may simply be imprudent to pursue the long-term project at all.

What the above discussion indicates is that social coordination has important prudential value. It makes sense, from a purely self-interested perspective, to grant to others certain basic rights in order to secure those basic rights for oneself. In so doing, it becomes much easier to pursue one's own life plans. Social coordination, particularly in the form of a scheme of basic rights and liberties, creates a background of stability that enhances everyone's ability to pursue their own life their own way. Insofar as everyone is interested in pursuing their own life their own way, everyone has at least some reasonably strong interest in establishing a scheme of basic rights and liberties.

The value of social coordination is not merely prudential. First, most individuals believe their plans and projects are morally valuable. We do what we do because we think it is worth pursuing. And so, a framework that helps us pursue those projects also has moral value, at least from the individual's perspective. Furthermore, a common social norm makes moral relations among free and equal people possible. ${ }^{26}$ And here is where the "moderate idealization" that convergence theorists impose on Members of the Public is important, for such idealized persons are understood to view their fellows as free and equal people 
and desire to properly respect that status by establishing and complying with publicly justified social norms. Absent a publicly justified social norm not only is conflict more likely but there are no morally appropriate responses to that conflict - no responses that properly respect others as free and equal; if there are no norms governing property, then when someone steals your property your resentment is inappropriate-it fails to regard the other as a free and equal person. ${ }^{27}$

That social coordination is of both prudential and moral value helps us understand further why the presence of widespread disagreement does not imply anarchy. People are not just interested in society being organized in accord with their own worldview; they are also interested in living in a society with others. ${ }^{28}$ This interest follows from both the moral and prudential value of social coordination. But, more generally, as social creatures, human beings are driven to live in a society and so are motivated, to various degrees, to reconcile their differences to maintain a stable society.

Individuals differ on the strength of their commitment to cooperation and of course on how they rank various options under consideration. Some individuals will stick to their preferred action or rule, even as a significant portion of society coalesces around an alternative; others, like Chris, will often join with the crowd, being strongly motivated to establish a common social arrangement or not being strongly committed to the norm she identifies as best. But as work in evolutionary game theory has shown, as more people coalesce around a specific norm or rule, the dissenters have stronger reason to also join in. ${ }^{29}$ For instance, insofar as Barry does not want to eat alone, then if Aly hops on board with Chris's recommendation of Indian food, he has even greater reason to accept that option than he did prior to Aly's assent. This implies that even those who are strongly committed to an alternative norm or rule, or are not terribly motivated to reconcile, can be brought on board as more members of society begin to coalesce. ${ }^{30}$ Thus,

27 Building in the requirement that one views one's fellow citizens as "free and equal" is common across (nearly) all political liberal theorists. Different theorists justify that idealization in different ways and identify different implications that follow from it. What I have suggested here largely follows Gaus's and Vallier's interpretations, which suggest that the idea of everyone as "free and equal" is baked into our practices of social morality. Rawls, in contrast, draws the idea from the "shared political culture" of a democratic society. See Gaus, The Order of Public Reason, ch. 4; Vallier, Must Politics Be War? ch. 3; Rawls, Political Liberalism, 29-34. Gaus, The Order of Public Reason, 398-99. Skyrms, Evolution of the Social Contract and The Stag Hunt and the Evolution of Social Structure. 
the presence of wide-ranging disagreement about what is best, which could perhaps set people at odds, is offset by their motivation to live together in a society.

What about the person whose projects include directing or constraining the behavior of others? ${ }^{31}$ This could be a person whose projects directly include wielding power over others or it could include a person who simply subscribes to certain views about how society should be structured - for instance someone who subscribes to traditional gender roles that fly in the face of sexual equality. To illustrate, we could add two new people to our restaurant example: Dave and Emily. Dave is of the view that unrelated men and women should not mingle in public and so while he, too, wants to eat dinner, he believes it is only acceptable for he and Barry to eat together. The women may also eat together but must do so separately. Emily, on the other hand, sees it as her role to promote the virtue of others by, in this case, ensuring that the group only eats vegan food. Like Aly, she herself wants to eat vegan food but, unlike Aly, she wants everyone else to also eat vegan food. Once we add Dave and Emily into the mix, it starts to look much less likely that the group can find common ground. People like Dave and Emily seem to pose a particular threat to the development of a liberal order.

There are a few things to say about this concern. First, the argument thus far was aimed at showing the possibility of agreement on core liberal institutions, not the possibility of agreement "all the way down." For someone like Dave, strong protection of the freedom of association allows him to form a voluntary community of people who prefer to live in accord with a traditional view about gender norms. This may not be all he wants, but if the alternative is no protection for his ability to form such communities-since plenty of people will have defeaters for making the entirety of society adhere to such norms-then it is likely to be justified for him. But if we were thinking more about a "downstream" policy_say paid parental leave-that can only be justified by the claim that it promotes sexual equality, then perhaps it cannot be publicly justified so long as we have people like Dave in the society. While I think it is unlikely that such a policy can only be justified in that way, to the extent that is true, then it does show that in a sufficiently diverse society some policies that are near and dear to certain progressives may be unjustified.

Someone like Emily, or Dave if he insists that all of society must adhere to his view of gender norms, may appear to pose a more significant problem. But here it is important to remember that it is coercion that stands in need of public justification. Indeed, the paid parental leave policy considered above may simply not be a policy in need of public justification just because it need not be coercive (depending on the details). On the other hand, Emily is advocating coercion-

31 I thank an anonymous reviewer for encouraging me to consider this issue. 
she is suggesting that others should be coerced into eating a vegan diet. Similarly, a Dave who insists that unrelated men and women cannot mingle in public is aiming to coerce others. In these situations, it is their proposal that must be publicly justified and they quite clearly cannot be in a sufficiently diverse society. Thus, such people pose little threat to others in terms of generating coercion.

Finally, consideration of people like Dave and Emily helps us extract some of the other key elements of convergence liberal theory. For one thing, the theory of moderate idealization that convergence liberals employ can help to eliminate some of the worst sorts of proposals from consideration. Proposals that depend on the rejection of the freedom and equality of all people are simply idealized away. ${ }^{32}$ This not only helps us eliminate some coercive proposals but also helps us potentially eliminate certain defeater reasons people may otherwise seem to have. As discussed earlier, convergence liberals do note an important asymmetry in their position - a lone dissenter may be sufficient to defeat a proposal but is never sufficient to adopt one-and they tend to want to minimize restrictions on defeaters. Nonetheless, that does not mean anything goes when it comes to defeaters. Moderate idealization still applies, and so some reasons that actual people will actually profess may disappear under idealization.

So, convergence liberalism, at least at the level of core liberal institutions, can handle concerns related to those who aim to dominate others or who hold views that imply restrictions on the behaviors of others. This does not eliminate the possibility that such concerns may function as defeaters for downstream policies and, indeed, beginning in the next section we will focus on moving more toward downstream policies to see what sorts of resources convergence liberals have to handle those sorts of issues. But the existence of such people does not impugn the ability to at least get the basic liberal project off the ground.

\section{CLASSICAL LIBERALISM AND THE MIN-ARCHY OBJECTION}

Those who level the anarchy objection against convergence liberalism suggest that because moderately idealized members of the public are still quite diverse, no law or social arrangement will pass the test set down by the PJP. The preceding discussion established that this need not be the case. Even in a sufficiently diverse society, everyone has sufficient reason to endorse at least the core institutions of liberalism. This is especially so since core liberal institutions, such as schemes of private property and rights to privacy and freedom of expression "economize on collective justification." 33 Rather than seeking a substantive com-

32 Gaus, The Order of Public Reason, 279.

33 Gaus, The Order of Public Reason, 374. 
mon viewpoint in the face of increasing diversity, liberal institutions only require a minimal common agreement-that within certain realms the evaluative standards of the individual are authoritative. Thus, rather than having to forgo acting in accordance with one's own conception of the good, in order to live in society, liberal institutions secure significant protections for those pursuits.

Thus far I have argued that we should reject Enoch's second premise-it is simply not true that just because everything is controversial nothing will be justifiable to all. But someone leveling the anarchy objection may reasonably retort, "Sure, you have shown that a minimal state can be vindicated against anarchy, but my real concern with convergence liberalism is that it cannot vindicate any more than that minimal state." By setting the bar on justification for coercion so high, those members of the public who strongly oppose state coercion-classical liberals or libertarians - will always block the justification of laws or social institutions that have tended to define the modern liberal state: arrangements that establish the illegality of discrimination and the provision of social welfare, for instance. ${ }^{34}$ Indeed, most (perhaps all) of those who level the anarchy objection tend to be in favor of various redistributive or welfare schemes and so, for them, a theory of political legitimacy that rules out their preferred schemes is a theory that should be rejected.

On this version of the anarchy objection, which we may call the "min-archy" objection, convergence liberalism makes libertarians effective "dictators" and, for that reason, should be rejected. In order to respond to this version of the objection, I will now argue that Enoch's first premise- that among moderately idealized persons everything is controversial—should be rejected. In particular, what Gerald Gaus has called the "perspective of agency" is shared among all members and can provide the basis for the possible legitimacy of redistribution and welfare rights or protections. I will further suggest that the min-archy objection should force convergence liberals to refine their model. In particular, there is disagreement among public reason liberals in general, and convergence liberals in particular, over the "scope" of public justification - that is, what stands in need of justification. For some, it is specifically laws that stand in need of justification, while others take a wider perspective and claim that all social coercion stands in need of justification. As I will suggest, it is only this wide-scope model of convergence liberalism that can wholly overcome the min-archy objection and so convergence liberals should extend the PJP to non-state coercion as well. ${ }^{35}$

Raz, "Facing Diversity," 47; Lister, "Public Justification and the Limits of State Action," 15356.

35 Interestingly, I also think that the "narrowest" scope view-that only "constitutional essentials and matters of basic justice" stand in need of public justification-may also overcome 


\section{MODERATE IDEALIZATION AND SHARED REASONS}

Each member of the public has her own plans and projects, which are partly determined by her conception of what makes for a good human life (which includes a conception of morality more generally). Because in a pluralistic society we regularly run up against different ways of living, and our own way of living is challenged and open to revision, we all cannot help but understand ourselves as deliberative agents. ${ }^{36}$ Thus, as Gaus suggests, despite our significant disagreements, we all share in the perspective of agency. By this he does not mean we view ourselves as "autonomous" agents in any thick sense, but simply that we all see our "actions as following from [our] own deliberations" even if those deliberations are "unreflective, traditional, or superstitious." ${ }^{37}$ Insofar as we view ourselves as naturally free, we accept that we are agents. Whether we embrace the sort of individuality Mill advocated for or defer to authority, we are deliberating (at least in a thin sense) about how our lives should go and making choices based on those deliberations.

All people, at the level of moderate idealization, can be understood to share this perspective of agency - they all view themselves as agents, even if they disagree about everything else. This follows quite naturally from the starting point of public reason — that all persons are free and equal — and from recognizing that the whole enterprise of requiring justification assumes that the individual is an agent. If an individual is not an agent, if her actions do not follow from her own belief-value set, her own deliberations, her own choices, then there is simply no reason to worry about justifying coercion to her. It is because coercion, when unjustified, aims to usurp the authority of the individual agent that it must be justified. In this way, it is simply not possible to escape the perspective of agency.

This shared perspective of agency forms the basis, in the convergence tradition, of the justification of the core liberal institutions. Indeed, the perspective of agency was simply assumed in my earlier defense of liberal institutions when I emphasized the value that all people place on pursuing their own projects (i.e., exercising their agency). But the appeal to the perspective of agency does more than this. It is from this noncontroversial shared perspective that we can begin to generate other core elements of the modern liberal state. Now, importantly, that all members of the public can be understood to share this perspective, and there-

the min-archy objection. However, I am not familiar with any convergence liberal who adopts that position in the debate. Nearly everyone seems to think Rawls was wrong to restrict the scope of public justification in this way.

Gaus, The Order of Public Reason, 337. 
fore to share the set of reasons that that perspective generates, does not mean that they will always come to the same conclusions about matters where those reasons are relevant. This shared perspective sits aside various unshared perspectives, and although the shared perspective of agency generates very strong reasons - given its centrality to all other elements of an individual's belief-value set-those reasons still must compete with the reasons generated by various other commitments each individual has. ${ }^{38}$ Nonetheless, identifying the sorts of reasons the perspective of agency generates and the sorts of coercive social arrangements those reasons support helps us understand how certain features of the modern liberal state can be legitimate.

Consider, most centrally, claims about welfare. A distinguishing feature of modern liberal societies is a commitment to the welfare of citizens. From the shared perspective of agency, we can begin to see how the eligibility of welfare protections becomes possible. An individual's ability to realize her agency can be impugned in all sorts of ways, including through starvation and ill health. As such, a commitment to one's own agency will lead one to endorse some basic welfare rights. As Gaus claims, "Members of the Public, aware only that they are agents, and of their reasons to maintain their agency and to be successful as agents, would insist not only on the freedom to pursue their agency but also the necessary means." ${ }^{39}$ Effective agency is the ability to potentially successfully achieve one's ends and requires more than mere noninterference. This is a position some libertarian thinkers explicitly endorse, and a position that all can be understood to hold under moderate idealization. ${ }^{40}$ That is because if one views oneself as an agent, and recognizes that one's agency is central to everything else one values-for one cannot successfully pursue any plans or projects if one's agency is eliminated-then one always has strong reason to preserve and even enhance her agency. In this way, everyone will be committed to basic welfare provisions.

The exact nature of those welfare provisions, however, is indeterminate. The shared perspective of agency provides but one set of reasons in favor of welfare schemes. Other, diverse considerations, such as desert, may count against

38 It should be added that, for the convergence theorist, not only must the shared reasons compete much more fully with unshared reasons, but the moderate idealization means there is a lot less that is "shared" than for the consensus theorist.

39 Gaus, The Order of Public Reason, 359.

40 Lomasky, Persons, Rights, and the Moral Community, 126. This also seems to be what Nozick has in mind in his discussion of permitting "boundary crossings" and compensation, although he does not clearly endorse a specific proposal. See Nozick, Anarchy, State, and Utopia, 78-87. 
certain sorts of welfare schemes. And, of course, the strength of one's concern with state coercion may alter one's rankings of various welfare proposals, and render some illegitimate. Nonetheless, at the level of moderate idealization all members of the public have some reason to support welfare protections, despite what an examination of actual political discourse may suggest. We may doubt this when we consider the libertarian who insists on very strong rights to private property and suggests that any sort of taxation or redistribution amounts to theft. However, as I have suggested above, the idealized libertarian would likely still support some basic welfare protections insofar as such protections preserve effective agency.

Moreover, it is worth remembering that even the libertarian is very concerned with the existence of a (minimal) state that protects his property rights. And so here we can leverage the great importance libertarians place on the protection of property rights to understand how a society, composed of libertarians and non-libertarians alike, would come to coordinate around some basic welfare protections, possibly including some redistributive schemes. This is because the public justification of a scheme of private property is inextricably linked to a discussion of welfare rights and the distribution effects of that scheme of private property. ${ }^{41}$ This makes sense given that it is the shared perspective of agency that justifies both abstract private property rights and abstract welfare rights. But this implies that, as members of the public rank the various options related to private property rights, they are also considering potential redistribution or welfare schemes. For some members of the public, an extensive scheme of private property rights with only minimal provision for the poor will be understood as exceedingly coercive, so much so that the costs outweigh the benefits and thus such a scheme is outside that member of the public's ranking of proposals. ${ }^{42}$

The forgoing argument draws on two important and related issues in political liberalism: issue individuation and justificatory dependence. In brief, it is an open question whether we should (for instance) consider the public justifiability of laws one by one or whether, at least some of the time, we must consider multiple laws as a single issue. There may be good reason to consider multiple laws as a single issue since there can be various interactive effects between the laws, and so whether a member of the public has sufficient reason to endorse one law will depend on the status of the other. And, of course, we can ask similar questions about a single piece of legislation: Should different parts of that

Mill, The Collected Works of John Stuart Mill, vol. 2, bk. 2; Brettschneider, "Public Justification and the Right to Private Property"; Gaus, The Order of Public Reason, 522. 
piece of legislation be considered independently? Or should the legislation be considered as a whole? Here I adopt what appears to be the common view in the literature: it depends. According to Gaus, we ought to consider multiple issues simultaneously - that is, the issues display justificatory dependence-if any member of the public's ranking of proposals would change upon considering the issues together and that would also change the social ranking of proposals. ${ }^{43}$

The justification of private property rights and the justification of abstract welfare rights are interdependent. Given the previous argument of the inextricable link between private property rights and abstract welfare rights, it should be clear that there will be at least some members of the public whose rankings of private property schemes will change depending on the justificatory status of abstract welfare rights (and vice versa). Since some people may reasonably hold that extremely strong protections on private property can only be justified if there are sufficient welfare guarantees, the social ranking of proposals will also vary depending on whether we consider the two issues separately or together. Thus, we cannot consider the justification of private property rights in isolation from consideration of welfare rights. Therefore, in constructing our social ranking, proposals with no welfare protections will be eliminated, as presumably will proposals with no protections for private property. We will then be left with a set of proposals that mixes, in various ways, protections for private property and welfare guarantees.

It is crucial here to remember how the eligible sets of proposals are constructed: the question is, would this proposal on the matter be better than no coordination at all? And so, given the libertarian's deep concern with the protection of property rights and the justificatory dependence of private property protections and welfare rights, we can see that when the alternative is no protection for private property, everyone is likely to have sufficient reason to endorse some welfare protections. Importantly, however, on this view it is not obviously the case that the state must be the guarantor of those welfare protections. ${ }^{44}$ It is an open question whether there may be non-state-based means to instantiate the abstract welfare rights. Nonetheless, given that instantiating any abstract private property protections will almost certainly require the state, and indeed if we imagine the question to be "What scheme of private property rights should the state enforce?" then it is very likely that some of the proposals in the social ranking will involve the state in both protecting private property rights and providing for basic welfare. ${ }^{45}$

43 Gaus, The Order of Public Reason, 495.

44 I thank an anonymous referee for encouraging me to clarify this point.

45 Additionally, if one adopts a view where only state-based coercion stands in need of public 
And so, even if Enoch were correct that nothing can be justified to all if everything is controversial, he is wrong to assert that among moderately idealized members of the public everything is controversial. The perspective of agency is not, in itself, controversial. And although precisely what it will be taken to support will vary among individuals, it can nonetheless provide the basis of establishing some of the core features of modern liberal welfare states and, therefore, provide the basis for escaping the minimal state.

\section{SOCIAL COERCION AND THE WIDE SCOPE OF PUBLIC JUSTIFICATION}

The preceding discussion of welfare rights can be understood as part of a broader concern some may have with convergence models: that they cannot justify the sorts of social justice policies that many contemporary progressives advocate. Policies relating to the welfare of the poor are but one subset of concerns we may have in society. We may also be concerned with the protections of various vulnerable populations and so advocate for anti-discrimination policies. And yet some in our society have suggested that anti-discrimination and related civil rights policies, including the landmark Civil Rights Act, are instances of unjustified coercion. ${ }^{46}$ The claim here is that such protections involve coercing private citizens, or privately held businesses, to change their practices in ways incompatible with their personal commitments. Requiring businesses to serve people regardless of race, for instance, coerces business owners because it tells them they must act in a certain way or risk punishment. More generally, the worry may be that anti-discrimination policies are unlikely to be publicly justified and so even if convergence models do not risk anarchy, they risk what many would identify as a significantly unjust society.

This sort of concern is well founded if applied to certain versions of the convergence view. If only laws, or state-based coercion, stand in need of public justification, then it does make it difficult to justify anti-discrimination policies. ${ }^{47}$ For instance, policies that make it illegal to refuse service to people based on race, or sexual orientation, are straightforwardly coercive.

justification, and that includes state-based protections for private property, then it is obvious that the state will be involved in the related welfare protections as well. But, as I argue in the next section, we should not hold that only state-based coercion stands in need of public justification.

46 Both Rand Paul and Ron Paul have said things to this effect. See, e.g., Rand Paul's 2010 interview with the Courier-Journal at https://www.courier-journal.com/videos/opinion/ 2014/07/09/12376813.

47 Vallier's position in Liberal Politics and Public Faith is an example of a narrow convergence view. He expands the view in his later work. 
But here the remedy for the problem is to recognize that it is not just statebased coercion that stands in need of justification. Neither Rawls nor Gaus restricts the principle of public justification to state-based coercion. ${ }^{48}$ For as Mill argued, the forum of public opinion, which may be exercised by the majority, can represent a "social tyranny more formidable than many kinds of political oppression, since, though not usually upheld by such extreme penalties, it leaves fewer means of escape, penetrating more deeply into the details of life, and enslaving the soul itself." Following this insight, a "wide" convergence model expands the scope of public justification to social coercion as well. And in so doing, we can take account of many of the social justice concerns that may otherwise worry us.

Socially enforced discrimination is coercive. ${ }^{50}$ It can significantly restrict the life prospects of various citizens and seems quite obviously to fail to regard many citizens as free and equal. If we follow Mill (and, as I have suggested, Rawls and Gaus) and place such social discrimination within the purview of public justification, then we get a better view of the relationship between discriminatory social arrangements and anti-discrimination laws. In particular, we can evaluate the coercive social arrangements as themselves unjustified-for surely those being discriminated against do not have sufficient reason to endorse them. But, further, we can evaluate the anti-discrimination laws, depending on how they are crafted, as either coercion neutral or net coercion reducing. This is because the laws themselves, while having coercive components, would presumably correct for the unjustified coercion already present in the society. Of course, the details will matter here and not just any anti-discrimination legislation would be acceptable. The central point is that this sort of explanation of the role and effect of anti-discrimination laws fits better with our intuitive understanding of the laws.

Anti-discrimination legislation is one way state coercion can be a remedy for unjustified social coercion, but other "social justice" causes may also be plausibly understood as calls for the state to take coercive action to reduce or eliminate unjustified social coercion. ${ }^{51}$ Here, the right way to understand the situation is that (at least) those who are being (for instance) discriminated against by way of various social norms do not have sufficient reason to endorse that social coer-

\section{Rawls, Political Liberalism, 269; Gaus, The Order of Public Reason.}

Mill, “On Liberty”, 220.

While I think this claim is largely noncontroversial, Colin Bird defends it in detail ("Coercion and Public Justification").

For instance, I argue elsewhere that this route can make sense of calls for stricter animal protections by indicating that various property norms surrounding animals are actually unjustified. 
cion. The social coercion of discrimination can come in various forms, but often involves norms that limit opportunities and access for certain groups of people and is backed by the threat of social sanction or violence. For instance, informal segregation involves social norms that restrict where certain people may go. That there already exists social coercion for a given issue alters the coercion costs of state-based intervention. The mistake some self-proclaimed, liberty-loving politicians make, in rejecting anti-discrimination legislation, is to view the situation without the legislation as noncoercive (regarding the relevant issue). It is not, in fact, noncoercive; it is just that they are not the ones who are being coerced. ${ }^{52}$

Importantly, the argument I have just given in favor of (some) social justice policies directly counters the conclusion most (perhaps all) convergence liberals draw about their own view. They often claim that their theory shows a "classical liberal tilt" and Gaus goes so far as to claim that "principles of social justice [are] not stable under full justification." ${ }^{53}$ Now, I am not impugning all of the specific arguments he makes there regarding specific abstract social justice principles; he may be right as far as those go. But the argument I have given in this section gives us a different way to think about social justice issues than he discusses. He focuses on whether basic principles of social justice may be justified early in the "order of justification," where other basic rights are justified. The argument I made here does not depend on social justice principles being justified in this way, but instead suggests that we can often think about calls for "social justice" as being calls for a net reduction in coercion by emphasizing that existing (usually social) coercion is illegitimate. In this way, I am employing what Gaus calls the "testing conception" of public justification that focuses on evaluating whether existing social norms are morally acceptable rather than making positive arguments for the moral acceptability of new forms of coercion. ${ }^{54}$ In this way, I am bringing more in line the strong anti-coercion view commonly associated with classical liberalism and the strong pro-equality view commonly associated with social justice liberalism. In effect, I agree that an emphasis on public justification will have a "classical liberal tilt," but reinterpreting what that means by emphasizing the social coercion as well as the state-based coercion. In short, whereas many

Importantly, this claim is not universal. Many instances of social discrimination are certainly coercive, as when individuals are excluded from certain employment or educational opportunities due to race or gender, but merely limiting freedom-as when private organizations restrict membership-need not be construed as coercive. I thank an anonymous referee for encouraging me to clarify this claim.

53 Gaus, The Order of Public Reason, 521. Although this quotation can be found later in the book, he refers to the arguments he makes earlier, 359-68.

54 Gaus, The Order of Public Reason, ch. 21. 
have taken convergence liberalism to be quite hostile to policies and views commonly associated with social justice liberalism, the approach I have taken shows that there is plenty of room in convergence liberalism for social justice liberalism, suitably interpreted.

Before moving on, it is worth further highlighting the implications of this argument. Both Mill's liberalism and contemporary "social justice" liberalism are often identified, by political liberals, as "comprehensive liberalisms" that depend, for instance, on controversial views about human nature or motivation or thick conceptions of political concepts like equality. This is problematic, we are told, because not all members of a diverse public will hold those controversial views and thus the liberalism that results will not be publicly justified and hence, in Rawls's terms, will not be stable for the right reasons. Political liberalism has often been seen as a competing approach to these sorts of comprehensive liberalisms, working to eliminate any controversial metaphysical or ethical commitments in favor of purely "political" conceptions of the person (or citizen) and justice, among other concepts. What I have suggested, however, is that the views are much closer than many political liberals have suggested. Not only must political liberals integrate some of the deeper insights about the nature of society and social norms that comprehensive liberals like Mill identified, but convergence liberals in particular must reconsider the relationship between their view and various calls for social justice in modern society. While convergence liberalism may still have a "classical tilt," the tilt is not as great as Gaus and other convergence liberals have suggested.

\section{CONVERGENCE LIBERALISM AND THE MODERN WELFARE STATE}

The modern liberal state does much more than merely protect private property rights. While we should not think that all that the modern liberal state does is justified, we may also reasonably worry that a view of political legitimacy that vindicates only the minimal state has got something wrong. ${ }^{55}$ The various welfare institutions of the modern liberal state do not seem obviously illegitimate, and so it should at least be an open question whether, in any given society, theyor other versions of them — can be justified.

I have suggested that a convergence liberalism with a wide scope of justification does, indeed, leave it an open question as to whether welfare institutions and other social justice policies are justified. Critics are correct to oppose convergence models that restrict the scope of public justification to state action,

55 Rawls, Political Liberalism, 262-65; Lister, "Public Justification and the Limits of State Action." 
as these inappropriately ignore Mill's insight regarding social tyranny. Thus, in moving forward with the public reason project, our focus should be on models with a wide scope.

A vindication of core liberal institutions over anarchy and of something approximating the modern liberal welfare state over the minimal state should render the min-archy objection toothless. In the vast majority of cases where we may want to forgo public justification in the name of justice-we do not think we need to justify anti-racism policies to the racist-a model of convergence public reason can make sense of how we can have both public justification and justice.

Enoch is a staunch critic of the entire public reason project. He has posed various objections to the consensus model, objections that convergence theorists are largely happy to accept. But he is wrong to conclude that the public reason project is hopeless and should be abandoned. Although the consensus model may fail, the convergence model remains an attractive alternative. Not only can it vindicate classical liberalism, but it can also vindicate the modern liberal welfare state. In a contemporary society, characterized by significant, but reasonable, disagreement, the convergence model of public reason can provide the framework for distinguishing legitimate from illegitimate coercive social arrangements. ${ }^{56}$

Cleveland State University
m.schultzbergin@csuohio.edu

\section{REFERENCES}

Bird, Colin. "Coercion and Public Justification." Politics, Philosophy and Economics 13, no. 3 (August 2014): 189-214.

Brettschneider, Corey. "Public Justification and the Right to Private Property: Welfare Rights as Compensation for Exclusion." Law and Ethics of Human Rights 6, no. 1 (December 2012): 119-46.

Eberle, Christopher J. "Consensus, Convergence, and Religiously Justified Coercion.” Public Affairs Quarterly 25, no. 4 (October 2011): 281-303.

Enoch, David. "Against Public Reason." In Oxford Studies in Political Philosophy,

56 Earlier versions of this paper, or ideas contained within, were presented at the Rocky Mountain Ethics Congress and Adelphi University. I am grateful to the participants at each for their comments. I would also like to thank Michael Weber, Kevin Vallier, and John Basl for feedback on earlier drafts, as well as the referees and editors of this journal. 
vol. 1, edited by David Sobel, Peter Vallentyne, and Steven Wall, 112-42. Oxford: Oxford University Press, 2015.

Gaus, Gerald. "On Two Critics of Justificatory Liberalism: A Response to Wall and Lister." Politics, Philosophy and Economics 9, no. 2 (May 2010): 177-212. . The Order of Public Reason: A Theory of Freedom and Morality in a Diverse and Bounded World. New York: Cambridge University Press, 2012.

. The Tyranny of the Ideal: Justice in a Diverse Society. Princeton: Princeton University Press, 2019.

Gaus, Gerald, and Kevin Vallier. "The Roles of Religious Conviction in a Publicly Justified Polity: The Implications of Convergence, Asymmetry and Political Institutions." Philosophy and Social Criticism 35, nos. 1-2 (January/ February): 51-76.

Lister, Andrew. "Public Justification and the Limits of State Action." Politics, Philosophy and Economics 9, no. 2 (May 2010): 151-75.

Lomasky, Loren E. Persons, Rights, and the Moral Community. New York: Oxford University Press, 1990.

Mill, John Stuart. The Collected Works of John Stuart Mill, vol. 2, The Principles of Political Economy with Some of Their Applications to Social Philosophy, edited by J.M. Robson. Toronto: University of Toronto Press, 1965.

- On Liberty. In Collected Works of John Stuart Mill, vol. 18, Essays on Politics and Society, edited by J. M. Robson, 213-310. Abingdon, UK: Routledge, 2014.

Nozick, Robert. Anarchy, State, and Utopia. New York: Basic Books, 2013.

Quong, Jonathan. Liberalism without Perfection. Oxford: Oxford University Press, 2011.

- "Liberalism without Perfection: Replies to Gaus, Colburn, Chan, and Bocchiola." Philosophy and Public Issues 2, no. 2 (2012): 51-79

Rawls, John. Political Liberalism, 2nd ed. New York: Columbia University Press, 2005 .

. A Theory of Justice, rev. ed. Cambridge, ma: Belknap Press, 1999.

Raz, Joseph. "Facing Diversity: The Case of Epistemic Abstinence." Philosophy and Public Affairs 19, no. 1 (Winter 1990): 3-46.

Skyrms, Brian. Evolution of the Social Contract. Cambridge: Cambridge University Press, 1996.

- The Stag Hunt and the Evolution of Social Structure. Cambridge: Cambridge University Press, 2003.

Vallier, Kevin. "Against Public Reason Liberalism's Accessibility Requirement." Journal of Moral Philosophy 8, no. 3 (January 2011): 366-89. 
—. "Convergence and Consensus in Public Reason." Public Affairs Quarterly 25, no. 4 (October 2011): 261-279.

- "In Defence of Intelligible Reasons in Public Justification." Philosophical Quarterly 66, no. 264 (July 2016): 596-616.

- Liberal Politics and Public Faith: Beyond Separation. New York: Routledge, 2014 .

- Must Politics Be War? Restoring Our Trust in the Open Society. New York: Oxford University Press, 2019.

Vallier, Kevin, and Fred D’Agostino. "Public Justification.” In Stanford Encyclopedia of Philosophy (Spring 2014). https://plato.stanford.edu/archives/ spr2014/entries/justification-public.

Wall, Steven. "Public Reason and Moral Authoritarianism." Philosophical Quarterly 63, no. 250 (January 2013): 160-69.

Wendt, Fabian. Compromise, Peace and Public Justification: Political Morality Beyond Justice. London: Palgrave Macmillan, 2016. 